\title{
A escravidão depois da escravidão: a questão do trabalho compulsório na constituição das organizações internacionais no período de entreguerras
}

\author{
Norberto O. Ferreras[1]
}

\begin{abstract}
Resumo
O presente artigo trata da forma com que os organismos internacionais surgidos depois da Primeira Guerra Mundial lidaram com a questão da escravidão e com o trabalho forçado, criando âmbitos para discutir essas práticas, assim como um arcabouço legal internacional para tratar disso. Para poder estabelecer esses espaços de discussão e reflexão sobre a escravidão, foram definidas as áreas de incumbência entre a Sociedade de Nações $(\mathrm{SdN})$ e a Organização Internacional do Trabalho (OIT). A primeira lidou com o tráfico de pessoas e a escravidão, definida esta como a propriedade da pessoa. A OIT especializou-se no trabalho forçado e no trabalho nativo. Cada uma delas teve um papel decisivo na constituição de instrumentos legais universalizados em cada caso.
\end{abstract}

Palavras-chaves: escravidão; trabalho forçado; organizações internacionais.

Slavery after slavery: The debate on compulsory labor in the constitution of international organizations process in the interwar period

\begin{abstract}
This article deals with the way in which the international organizations that emerged after World War I managed the issue of slavery and forced labor, creating areas to discuss these practices, as well as an international legal framework to address the same. In order to establish these spaces for discussion and reflection on slavery were set the task of areas between the League of Nations (LoN) and the International Labor Organization (ILO). The first dealt with human trafficking and slavery, defined this as the property of the person. The ILO has specialized in forced labor and native labor. Each of them had a decisive role in the creation of legal instruments universalized in each case.
\end{abstract}

Keywords: slavery; forced labor; international organizations.

\section{La esclavitud después de la esclavitud: la cuestión del trabajo forzoso en la constitución de las organizacio- nes internacionales en el periodo de entreguerras}

\section{Resumen}

Este artículo se ocupa de la forma en que las organizaciones internacionales surgidas tras la Primera Guerra Mundial trataron la cuestión de la esclavitud y del trabajo forzado, desarrollando áreas para discutir estas prácticas, así como un marco jurídico internacional para hacer frente a las mismas. Con el fin de establecer estos espacios de discusión y reflexión sobre la esclavitud fueron impuestas la división de tareas entre la Sociedad de las Naciones ( $\mathrm{SdN}$ ) y la Organización Internacional del Trabajo (OIT). La primera trataba con el tráfico de personas y la esclavitud, definida esta como la propiedad de la persona. La OIT se especializó en el trabajo forzado y en la mano de obra nativa. Cada uno de ellos tuvo un papel decisivo en la creación de instrumentos legales que universalizaron a cada abordaje.

Palabras claves: esclavitud; trabajo forzado; organizaciones internacionales.

L'esclavage après que l'esclavage: la question du travail forcé dans la constitution des organisations internationales dans la période entre les deux guerres

\section{Résumé}

Cet article traite de la façon dont les organisations internationales qui ont émergé après la Première Guerre mondiale a abordé la question de l'esclavage et du travail forcé, le développement des zones pour discuter ces pratiques et un cadre juridique international pour y remédier. Afin d'établir ces espaces de discussion et de réflexion sur l'esclavage, ils ont été imposées répartition des tâches entre la Société des Nations (SdN) et l'Organisation Internationale du Travail (OIT). Le premier a traité de la traite des êtres humains et l'esclavage, défini ce que la propriété de la personne. L'OIT devint une institution spécialisée dans le travail forcé et la main-d'œuvre indigène. Chaque a joué un rôle dans la création d'instruments juridiques universalisés chaque approche.

Mots-clés : esclavage ; travaux forcés ; organisations internationales. 
"Why brought he us from bondage, Our loved Egyptian night?"

Rudyard Kipling, "The white man's Burden: The United States and The Philippine Islands"2

Imediatamente após a Primeira Guerra Mundial, abriu-se um período de reorganização das relações internacionais. As vinculações políticas entre os países foram encaminhadas rapidamente e resolvidas com o estabelecimento da Sociedade de Nações (SdN). Para auxiliar a Sociedade, foram criados outros organismos, como a Organização Internacional do Trabalho (OIT), para atender aos debates urgentes que emergiam como consequência da guerra. A principal questão social europeia, o trabalho organizado, devia ser considerada. Outra questão que recebeu a atenção dos vencedores foi a continuidade da missão civilizadora nos territórios coloniais, alguns dos quais correspondiam às potências derrotadas. A partilha desses territórios vinha junto com a justificativa da luta contra três grandes flagelos: o tráfico de armas, álcool e escravos.

Neste texto, trataremos da construção da aproximação à questão da escravidão depois da abolição do tráfico nos países ocidentais no período de entreguerras. Para isso, abordaremos dois grandes segmentos: o tráfico e o trabalho forçado, que às vezes foram tratados como parte de um mesmo fenômeno e em outras como questões diferentes.

Deve ficar claro que analisaremos a forma com que os organismos internacionais construíram uma categoria legal e discursiva que se mantém praticamente inalterada até o presente. Os organismos pretendiam que a escravidão e o trabalho forçado fossem um todo homogêneo, incluindo o tráfico de pessoas com finalidades sexuais e o confinamento de seres humanos para se apropriar de sua força de trabalho. A pretensão desses organismos estava vinculada à elaboração de uma normativa legal, pelo que o universo da escravidão foi reduzido a essas duas experiências. Mas "escravidão" era, e é, um termo fugidio, não se referindo a uma única prática, e englobava realidades diferentes, com seus nomes e regulações práticas (Grenouilleau, 2014, p. 13). Feita essa ressalva, vamos ver a forma com que os organismos internacionais construíram uma legislação internacional para tratar da questão.

II

A escravidão do século XIX concluiu com os tratados de paz que se seguiram ao fim da Primeira Guerra e da Conferência de Paris. No Acordo de Versalhes

2 "Oh! Nossa amada noite egípcia,/ por que nos tirastes do cativeiro?" (tradução nossa). A poesia de Kipling foi publicada em 1899 em Nova York. Disponível em: <http://legacy.fordham.edu/halsall/mod/kipling.asp>. Acesso em: 20 fev. 2016. 
e nos diferentes acordos de paz por países, foi incluída a questão da escravidão como um problema a ser resolvido no marco dos convênios internacionais e pelo acordo entre as diversas nações. Pretendia-se iniciar uma nova etapa.

O avanço em relação a um novo sistema de coexistência foi alcançado com a criação da $\mathrm{SdN}$ e de seus organismos auxiliares. A cláusula 22 do Convênio de sua criação estabelecia o fim do tráfico de escravos, de armas e de licor, especialmente na África Central (League to Enforce Peace, 1919, p. 13). Em paralelo, foram assinados três tratados complementares contra o tráfico de escravos, de armas e de álcool, que substituíram os tratados de Berlim (1890) e de Bruxelas (1895) (France, Ministère des Affaires Etrangères, out./dez. 1922, n. 4, p. 763-766). Pouco depois ficou evidente que esses acordos eram insuficientes.

A primeira medida dos organismos na direção dos acordos foi a redistribuição das colônias dos países derrotados entre os vitoriosos por intermédio de um mandato da SdN. Os mandatos estavam divididos em três classes: A, B e C. Os mandatos de "Classe A" englobavam as antigas regiões do Império Otomano que poderiam vir a ganhar autonomia e até independência sempre que fossem administradas por um período por alguma potência, como a GrãBretanha ou a França. Nos mandatos de "Classe B" estavam as antigas colônias da Alemanha na África Central, que precisavam de um controle mais estrito porque eram os territórios mais sensíveis em relação ao tráfico de escravos, armas e álcool (League of Nations, 1920b, v. II, p. 355). Finalmente, nos mandatos de "Classe C" estavam a África sul-ocidental e as ilhas do Pacífico. Esses territórios deviam ser incorporados como territórios próprios dos países mandatários e submetidos às suas leis. A escassa população e os povos indígenas existentes precisavam da tutela das potências para ser civilizados. ${ }^{3}$ Ao eliminar a escravidão nessas regiões, seus povos alcançariam a civilização, porque a linha que demarcava a fronteira entre civilizados e bárbaros estava sendo construída desde o século XIX. Esse argumento seria cada vez mais utilizado como justificativa da situação colonial (Drescher, 2012, p. 94-96).

O primeiro problema a enfrentar era conceitual: o que significava "escravidão"?

Na primeira assembleia da SdN, realizada em 1920 (League of Nations, 1920a, v. I, p. 180), o secretário-geral pediu a realização de um encontro em junho do ano seguinte para tomar decisões sobre a escravidão chamada "branca", ou seja, o tráfico de mulheres e crianças. O chamado ao encontro foi acompanhado por um questionário sobre o tipo de práticas sexuais públicas permitidas ou criminalizadas em cada país, indagando, por exemplo, se a prostituição era legal, se menores podiam se prostituir etc. Todos os países-membros receberam o questionário. Do encontro de 1921 participaram 34 países, quatro dos quais eram da América Latina: Brasil, Chile, Panamá e Uruguai. Como resultado, foi recomendado abolir o tráfico de mulheres e crianças, sendo o acompanhamento dos resultados e a punição estabelecidos por meio de uma nova organização com integrantes da $\mathrm{SdN}$ e assessores provenientes de grupos

${ }^{3}$ Ver uma apresentação e análise do sistema de mandatos estabelecidos no início do funcionamento da Liga em Stahn (2008, cap. 2: "The mandate system of the League of Nations"). 
interessados na questão, como associações feministas ou religiosas. Também foi decidido substituir a expressão "tráfico da escravidão branca" por "tráfico de mulheres e crianças", o que representava uma modificação na utilização do termo "escravidão" (League of Nations, 1921, v. II, p. 432-462).

\section{Deve ficar claro que analisaremos a forma com que os organismos internacionais construíram uma categoria legal e discursiva que se mantém praticamente inalterada até o presente}

Entre 1922 e 1923, a Sociedade realizou uma nova consulta sobre a escravidão, dessa vez relacionada com o trabalho indígena ou nativo, em que parecia possível a existência de trabalho forçado. As poucas respostas recebidas foram deliberadamente ambíguas. Nesse contexto, a SdN decidiu constituir uma comissão para pensar políticas antiescravistas. A comissão, batizada de “Comissão Temporária sobre a Escravidão", foi instalada em 1924 para investigar as denúncias existentes e foi formada por membros dos seis grandes países coloniais: Grã-Bretanha, França, Itália, Portugal, Holanda e Bélgica. A eles corresponderia controlar as práticas permitidas de recruta e retenção dos trabalhadores e inibir a possibilidade do restabelecimento da escravidão. Um representante extraordinário devia ser nomeado na comissão para atuar como um controle externo. O designado foi o secretário-geral da OIT, o francês Albert Thomas, conhecido antiescravista. ${ }^{4}$

A comissão transformou a escravidão em uma temática relevante para a Sociedade, dado que mapeou todas as formas de cerceamento da liberdade existentes, entre elas: o empréstimo de pessoas para pagamento de dívidas, a servidão, o matrimônio forçado, o casamento arranjado de crianças, a transferência ou adoção de crianças para sua exploração, o trabalho por dívidas, a peonagem e a obrigação de plantar ou semear determinados produtos. Também verificou se essas formas eram temporárias ou permanentes. A comissão compilou legislações nacionais para avançar na elaboração de uma convenção própria da SdN que considerasse as diversas tradições nacionais (Allain, 2008, p. 32-33; Miers, 2011, p. 7).

A Etiópia decretou o fim do tráfico e a posse de pessoas em 1923, preocupada com a movimentação da SdN e com o envio de uma provável inspeção. Com a medida da Etiópia, nenhum país-membro da Sociedade consentia em qualquer forma de escravidão. ${ }^{5}$ Essa atitude encorajou as associações

\footnotetext{
${ }^{4}$ A lista dos membros da Comissão Temporária se encontra em United States of America. Department of the State (1931, p. 3).

${ }^{5}$ A abolição da escravidão na Etiópia foi condicionada pelas ameaças da SdN de transformá-la em um novo mandato. Em 1935, a continuidade de formas de cativeiro foi a escusa para uma tentativa italiana de intervir nesse país (Allain, 2012, p. 200-203).
} 
abolicionistas, como a Anti Slavery International, que passou a pressionar a SdN. A resposta foi a preparação de uma Convenção contra a Escravidão. A primeira versão foi apresentada em 1925 por lorde Robert Cecil, visconde de Chelwood, representante britânico e coordenador da comissão elaboradora. A primeira versão recebeu fortes críticas, principalmente de Portugal, contrário a qualquer tipo de regulamentação.

A proposta inicial de lorde Cecil era contrária a qualquer restrição da liberdade e foi sendo morigerada ao longo dos debates da comissão. Sua proposta alertava sobre a servidão doméstica e era enfática nos limites colocados ao trabalho forçado. Porém, a convenção devia resultar de um acordo entre os países colonizadores. ${ }^{6}$

Um ano depois, lorde Cecil admitia a dificuldade de impor certas cláusulas e aceitava algumas das mudanças propostas. Parte de suas propostas ficou de fora da convenção, como as referências ao tráfico de crianças e mulheres e a "servidão por dívidas". Essas duas formas de sujeição foram colocadas nos comentários, abrindo a possibilidade de intervenções posteriores. Os representantes portugueses defendiam a manutenção de algumas formas de trabalho forçado, como existiam em suas colônias. Por causa dessa pressão, a recruta de nativos e o trabalho coercitivo continuaram sem grandes mudanças nas colônias portuguesas, e também nas inglesas, francesas, espanholas etc. Dando os nomes adequados a essas práticas, era possível mostrar o trabalho forçado desde a perspectiva de uma pedagogia civilizatória, e não desde a perda da liberdade. Mesmo assim, a convenção levava em consideração boa parte das demandas da Anti Slavery e das demais organizações que combatiam a escravidão (Allain, 2012, p. 105-106). ${ }^{7}$

III

Em setembro de 1926, a SdN aprovou a Convenção contra a Escravidão apresentada pela Comissão Temporária. Ela representava os acordos possíveis dentro da instituição. A convenção consta de 12 artigos que definem a escravidão como a propriedade da pessoa e desconsidera distintas formas de cativeiro analisadas nos trabalhos preparatórios. A convenção é congruente com a missão civilizadora do Ocidente. Vários países coloniais ou independentes, como Serra Leoa, Abissínia e as colônias portuguesas, aprovaram legislações acompanhando a convenção. ${ }^{8} \mathrm{O}$ trabalho da comissão foi determinar o que significava "escravidão", como aparece no artigo $1^{\mathrm{o}}$ :

${ }^{6}$ Ver League of Nations. Assembly, Sixth Committee (1925, p. 1 e 3).

${ }^{7}$ Ver League of Nations. Slavery Convention. United Nations Office at Geneva Library. Col. 277, Box 75, File 6, Genebra, 1926.

${ }^{8}$ United States of America. Department of the State (1931, p. 3). A convenção continua vigente, com algumas poucas alterações. 
Art. 1은

Aos fins da presente Convenção entende-se que:

1. A escravidão é o estado ou condição de um indivíduo sobre o qual se exercitam os atributos do direito de propriedade ou alguns deles.

2. A trata de escravos compreende todo ato de captura, aquisição ou cessão de um indivíduo para lhe vender ou cambiar; todo ato de cessão por venda ou troca de um escravo, adquirido para ser vendido ou trocado, e no geral todo ato de comércio ou de transporte de escravos. ${ }^{9}$

O aporte significativo da Convenção contra a Escravidão foi o de esclarecer e definir o que era escravidão em uma linguagem jurídica que pudesse ser utilizada em qualquer circunstância. O resto da convenção foi destinado à repressão do tráfico. Sem tráfico não haveria escravidão, pois esta estaria abolida em todos os países e colônias. O tráfico era uma prática ilegal e extraterritorial que afetava os migrantes ou levava a migrações forçadas. Igualmente, mesmo com todos os cuidados tomados e a sensibilidade do caso, sempre existia a "cláusula colonial", que desobrigava as potências de ter de cumprir plenamente os acordos de Genebra em seus territórios ultramarinos.

A aprovação da convenção, se não implicou necessariamente a extinção do trabalho forçado, da escravidão branca ou de outras formas de sujeição das pessoas, ao menos providenciou uma definição legal e uma normativa para ser aplicada. Lembrando que ela não implicava a substituição universal e imediata das legislações nacionais e locais. Se a Grã-Bretanha pressionava nessa direção, isso não queria dizer que não existissem outras normas e costumes em nível nacional, local ou regional para tratar do trabalho cativo.

A política abolicionista criava uma série de dificuldades nas relações coloniais, mantendo uma tensão permanente entre os representantes metropolitanos e os coloniais, e ainda entre as diferentes colônias. Combater o tráfico ou a escravidão de forma frontal implicava conflitos abertos com os poderes locais e a perda de parte do comércio colonial. Tratar a questão caso a caso implicava perder a força moral na luta abolicionista. Uma saída era combater a escravidão naqueles territórios que não eram colônias ou eram protetorados, como acontecia com as campanhas na Etiópia ou no Protetorado Britânico de Bechuanalândia (atual Botswana). A libertação formal dos escravos não tinha como consequência direta a liberdade individual. Muitas vezes, os libertos eram encontrados novamente na mesma situação e nos mesmos locais, embora não mais na qualidade de escravos. Pertenciam a outro estatuto trabalhista sem receber salários e sob algum tipo de coerção, mas isso não podia ser considerado escravidão. Sem posse ou propriedade da pessoa, não existia escravidão.

A Sociedade também tomou outras medidas, como o controle da peregrinação a Meca e a Medina, dado que alguns peregrinos financiavam a viagem transportando e vendendo escravos, mesmo que fosse um único. O reino

${ }^{9}$ League of Nations. Slavery Convention. Op. cit. 
de Hijaz (atualmente parte da Arábia Saudita), onde estavam localizados os locais sagrados do Islã, eram centros de recepção desses escravos (Lovejoy e Hogendorn, 1993, p. 264-286).

A possibilidade da perda do controle e da supremacia colonial obrigava a levar essa situação com cautela. $\mathrm{O}$ arcabouço legal aprovado acalmava a relação nas metrópoles com os influentes grupos abolicionistas e repassava as responsabilidades aos mandatários locais e aos administradores coloniais. Dessa forma, ganhavam-se tempo e possibilidades de ação. Depois desse impulso no resto da existência da $\mathrm{SdN}$, o conceito de escravidão foi sendo paulatinamente restringido ao tráfico de pessoas e à escravidão de mulheres e crianças.

Ao longo da década de 1930, a escravidão seria instrumentalizada como uma forma de reforçar o controle sobre os países africanos que se mantinham independentes. Tanto a Libéria quanto a Etiópia foram julgadas por não serem capazes de avançar em direção à civilização, em razão da continuidade da prática da escravidão (Allain, 2012, p. 206-207). As consequências foram duras para esses dois países. ${ }^{10}$

O que estava na convenção não necessariamente se aplicava àquilo que se observava na realidade. Em princípio, a escravidão clássica estava legalmente banida, mas eram detectados casos de escravidão doméstica e que eram considerados benévolos e uma prática tradicional, se comparados com a escravidão comercial. Muitos dos escravos domésticos provinham das disputas entre grupos tribais, e os capturados deviam prestar serviços a seus captores.

Embora os debates da Comissão Temporária não pudessem ser totalmente negligenciados em prol dos interesses específicos de alguns países, esses mesmos países não esperavam perder parte de seus privilégios coloniais. Isso se referia principalmente à questão do trabalho forçado nas colônias. Pelo artigo $5^{\circ}$ da convenção de 1926, admitiram-se formas de trabalho consideradas trabalho forçoso ou obrigatório sempre que gerassem benefício coletivo, tomando cuidado para não derivar em "formas análogas à escravidão":

Art. $5^{\circ}$

As Altas Partes contratantes reconhecem que o recurso ao trabalho forçado ou obrigatório pode ter graves consequências e se comprometem, cada uma no que diz respeito aos territórios submetidos à sua soberania, jurisdição, proteção, suserania ou tutela, a tomar as medidas necessárias para evitar que o trabalho forçado ou obrigatório produza condições análogas à escravidão. Fica entendido que:

1 - Sob reserva das disposições transitórias enunciadas no parágrafo $2^{\circ}$ abaixo, o trabalho forçado ou obrigatório somente pode ser exigido para fins públicos;

2ํ№s territórios onde ainda existe o trabalho forçado ou obrigatório para fins que não sejam públicos, as Altas Partes contratantes

\footnotetext{
10 Ambos passaram por controles e perda relativa da autonomia nacional. Ver League of Nations. Communication from the Government of the United States of America. Copy of memorandum delivered to the Liberian Consul General by the Secretary of State of the United States of America on November 17th, 1930. League of Nations Council, Document: C.L.3. 1931. VI.
} 
se esforçarão por acabar com essa prática, progressivamente e com a maior rapidez possível, e enquanto subsistir, o trabalho forçado ou obrigatório só será empregado a título excepcional, contra remuneração adequada e com a condição de não poder ser imposta a mudança do lugar habitual de residência; 3 o Em todos os casos, as autoridades centrais competentes do território interessado assumirão a responsabilidade do recurso ao trabalho forçado ou obrigatório. ${ }^{11}$

Assim, se o trabalho compulsório não era permanente, não era considerado escravidão. $\mathrm{O}$ trabalho análogo à escravidão era evitado pagando-se um salário ou limitando o tempo de permanência no local. Além do mais, muitas das tarefas realizadas eram consideradas para benefício dos próprios habitantes das colônias, pelo que eram consideradas "civilizatórias", porque traziam benefícios para suas comunidades de origem com a sua inserção no comércio internacional. A Comissão Temporária teve de aceitar que algumas formas de cativeiro fossem aprovadas por parte dos países europeus que se negavam a rejeitá-las como forma de perda da liberdade ou de propriedade. O trabalho coercitivo ficava disponível. ${ }^{12}$

Essa forma compulsória de trabalho só podia ser exigida em caso de utilidade pública, embora não fosse especificada. Era aceitável sempre que fosse temporária, remunerada e sem que o trabalhador tivesse de trocar de residência. Segundo a convenção, quem devia decidir sobre seu uso eram as autoridades centrais, pelo que acabava sendo uma questão política. Ante as dificuldades para estabelecer uma medida justa para esse tipo de trabalho, a questão foi remitida à OIT (United States of America. Department of the State, 1931, p. 3).

Igualmente, as dificuldades para estabelecer o que era "escravidão" levou a que, em 1936, a Comissão Temporária discutisse novamente o conceito de propriedade da pessoa na definição da escravidão. Nessa releitura, estabeleceu-se que a servidão e o trabalho por dívidas eram situações análogas à escravidão, e não escravidão propriamente dita, pelo que podiam ser praticados com certas restrições e atendendo às ações da OIT, como veremos adiante (Allain, 2012, p. 203).

IV

A OIT tinha sua própria agenda de trabalho, e nela estavam as formas de viabilizar o trabalho livre. Se a escravidão ficou na alçada da SdN, a OIT devia tratar das formas complementares que coagiam os indivíduos na condição de trabalhadores. O secretário-geral da OIT fez parte da Comissão Temporária e acompanhou seus debates. A OIT não podia incorporar escravidão a seu repertorio de temas porque não formava parte das questões próprias das relações de mercado. Pelo contrário, implicava a negação do mercado ao utilizar formas

"Ver League of Nations. Slavery Convention. Op. cit.

${ }^{12} \mathrm{lbid}$. 
coercitivas de sujeição dos indivíduos. Embora o mercado de trabalho não fosse visto como uma relação ideal, em que indivíduos se relacionam livremente e vendem sua força de trabalho sem pressões, mesmo assim não podiam estar coagidos por meios extraeconômicos para oferecer sua força de trabalho. A própria representação nas Conferências Internacionais do Trabalho (CIT) era corporativa e aceitava a agregação dos participantes por sua relação com os meios de produção: trabalhadores e proprietários, junto com os Estados. É essa a forma com que a OIT organizava e organiza a sociedade. O Estado é externo aos sujeitos e não se lhe reconhece um caráter de classe (Maul, 2007, p. 478).

\section{A Comissão Temporária teve de aceitar que algumas formas de cativeiro fossem aprovadas por parte dos países europeus que se negavam a rejeitá-las}

Acompanhar as reflexões da OIT sobre a coerção dos trabalhadores permite incorporar determinado setor da sociedade civil nesse âmbito que ampliou a visão sobre o trabalho forçado e incorporou vozes que não estavam nas outras instituições. O discurso das instituições governamentais, filantrópicas, confessionais ou de direitos humanos era a linguagem comum da época, mas a existência de outros atores na OIT deu maior complexidade aos debates. Os representantes dos trabalhadores apresentavam os casos que os governos tentavam evitar, ainda que para a situação colonial a realidade fosse mais complexa pela falta de representação. Porém, poucos países coloniais tinham representantes operários, entre eles a Índia e a África do Sul, e estes eram os porta-vozes dos conflitos entre trabalho livre e forçado.

Na reflexão da OIT, a perda da liberdade do trabalhador não estava vinculada à perda da liberdade individual, e sim à perda da liberdade econômica, ou seja, à capacidade de vender livremente a força de trabalho no mercado. Esse ponto preocupava tanto os trabalhadores nas colônias quanto os patrões, porque parte da força de trabalho era desviada para o usufruto de alguns poucos beneficiários, determinados pelo poder político local, que se reservavam parte do contingente trabalhista e desequilibravam o mercado de trabalho.

Por isso, para a OIT a escravidão significava uma forma extrema de degradação do ser humano e, portanto, não dizia respeito às suas ações, vinculadas ao trabalho legal. O bem protegido pela OIT era o trabalho, e a SdN protegia a liberdade. A escravidão levava à exploração do indivíduo de múltiplas formas, e não unicamente como trabalhador. Portanto, no caso dos trabalhadores deveriam ser pensadas outras categorias em que existia coerção, sem configurar a escravidão.

É por isso que nos debates para a aprovação de uma convenção sobre o trabalho forçado a palavra "escravo" foi utilizada de forma descritiva, e não analítica. Se a Sociedade tratava da questão da perda da liberdade e da escravidão 
como propriedade da pessoa, a OIT analisava as formas com que o trabalho resultava na perda da liberdade do trabalhador. "Propriedade" parece ser a chave para distinguir as duas perspectivas. ${ }^{13}$

A adoção pela OIT do trabalho forçado e da escravidão só teve início com os trabalhos da Comissão Temporária e com a sanção da convenção de 1926 contra a escravidão; até esse momento pouco havia sido produzido. A questão do trabalho forçado na OIT não foi discutida nas primeiras CIT. Desde 1922 o órgão de governo da OIT tinha decidido reunir informação sobre o tema, o que posteriormente subsidiaria as posições da OIT. O passo seguinte tinha sido a conformação de um grupo de expertos em 1926, o ano da aprovação da Convenção sobre a Escravidão da SdN.

Justamente o artigo $5^{\circ}$ dessa convenção levou a que a OIT tivesse uma posição mais ativa. $\mathrm{O}$ trabalho forçado foi admitido como caminho para a civilização, embora não pudesse ser utilizado sem uma série de ressalvas, que deviam ser claramente especificadas.

Até esse momento, essa instituição tinha voltado seus esforços ao trabalho urbano e industrial, sem que nenhuma de suas convenções ou resoluções levassem em consideração o trabalho rural ou a especificidade do trabalho nas colônias. ${ }^{14}$ Só foi depois da Convenção sobre a Escravidão da SdN que a OIT passou a analisar a questão dos trabalhadores indígenas, nativos e coloniais. Essa seria a base para tratar o trabalho forçado e ir além do Código do Trabalho Nativo (Native Labor Code - NLC) e que podemos associar à Cláusula Colonial. Segundo esta, às metrópoles era permitido não aplicar as normas que consideravam inadequadas nas colônias que administravam. ${ }^{15}$ Muitas medidas podiam ser ignoradas, criando um duplo standard legal entre as metrópoles e as colônias.

Na OIT, o debate sobre o trabalho forçado levou à abertura de uma nova frente de preocupação e de estudo. A ação dos representantes governamentais nas CIT foi a de minimizar a situação do trabalho nas colônias, aduzindo que não afetava as metrópoles ou os países independentes. A posição dos países metropolitanos estava na própria constituição da $\mathrm{SdN}$, que, tanto pelo artigo 22 do convênio da SdN quanto pelo artigo 421 do Tratado de Versalhes, lhes colocava como guardiões dos países que não tinham condições de se governarem sozinhos. E isso também permitia que tivessem a prerrogativa de decidir que legislação aprovada pela OIT podia ou não ser aplicada a cada realidade regional. Como diz o artigo 421 da Parte XIII do Tratado de Versalhes:

Os membros comprometem-se a aplicar as convenções a que tenham aderido de conformidade com o estabelecido da presente parte desse tratado, a aquelas das suas colônias ou posses e

\footnotetext{
${ }^{13}$ Nas recomendações e convenções, assim como nas resoluções, a expressão utilizada é "trabalho forçado". 14 No livro publicado pela OIT para comemorar seus primeiros 10 anos, reconheciam-se essa carência e a ênfase no trabalho urbano (International Labour Office, 1931, p. 221).

${ }^{15}$ O Código era conformado pelas convenções e recomendações aprovadas durante a década de 1930 e que estavam destinadas aos trabalhadores coloniais (Maul, 2007, p. 23-27).
} 
a aqueles de seus protetorados que não se governem plenamente por si próprios, mas com as seguintes ressalvas:

$1^{\circ}$ Que a convenção não seja inaplicável pelas condições locais; $2^{\circ}$ Que as modificações que fossem necessárias para adaptar a convenção às condições locais possam ser introduzidas nelas. Cada um dos membros deverá notificar à Organização Internacional do Trabalho a decisão que se propõe a tomar no concernente a cada uma das suas colônias ou posse ou cada um dos seus protetorados que não se governam plenamente por si próprios. ${ }^{16}$

A OIT tentava assimilar o trabalho forçado ao trabalho indígena; portanto, nessa aproximação devia ser considerado o fato de que esses eram trabalhadores especiais, que não estavam inseridos no mercado de trabalho. Não eram proletários, mas estavam em processo de proletarização. Essa condição transitória criava certa tensão no interior da OIT. Civilizar ou educar implicava a desagregação tribal pela via da incorporação no mercado de trabalho? Ou as comunidades nativas deviam ser preservadas no estado em que estavam? Os empresários e os países coloniais não tinham essa dúvida; as suas estavam na forma de agregar valor nas colônias sem trabalhadores. Segundo eles, não era possível civilizar sem que os nativos trabalhassem. Por isso, todos concordavam em que o trabalho era a condição necessária para levar o desenvolvimento aos territórios coloniais. A tensão em relação ao tema foi constante. ${ }^{17}$

A aprovação da Convenção contra a Escravidão de 1926, que contou com o assessoramento de Albert Thomas, levou a que a OIT incorporasse em sua agenda a questão do trabalho forçado, respondendo às perguntas que tinham ficado no ar. ${ }^{18}$

Foi nesse sentido que em 1926 o Native Labour Comittee da OIT encomendou uma pesquisa sobre o trabalho forçado entre os indígenas da África e da América, estabelecendo-se, assim, um vínculo causal entre o trabalho forçado e a situação colonial ou semicolonial. A abertura do debate permitiu que algumas disputas locais viessem à tona. O delegado trabalhista da Índia aproveitou o debate para denunciar que em seu país o governo permitia o trabalho forçado, o que foi negado pelo delegado governamental. Por sua vez, os delegados latino-americanos rejeitaram a iniciativa, porque negavam a existência do trabalho forçado nas Américas e entendiam que a restrição geográfica limitava um tema universal. O delegado do governo do Brasil, Fonseca de Montarroyos, sintetizou a posição dos latino-americanos. Ele afirmou que: “[...] essa Resolução é absolutamente inaceitável para nós porque está baseada na presunção de

${ }^{16}$ A Parte XIII é a Constituição inicial da OIT. O artigo 421 está disponível em: <http://avalon.law.yale.edu/imt/ partxiii.asp> (League Of Nations. The Versailles Treaty June 28, 1919: Part XIII. In: The Avalon Project) e o artigo $22 \mathrm{em}$ : <http://avalon.law.yale.edu/2Oth_century/leagcov.asp> (League of Nations. The Covenant of the League of Nations. In: The Avalon Project). Ambos os documentos foram acessados em: 15 mar. 2016.

${ }^{17}$ No livro comemorativo da década da OIT se apresentava a necessidade de considerar os distintos fatores implicados na contratação desses trabalhadores, como a economia familiar e os costumes nativos, dado que a contratação de um trabalhador implicava a reconfiguração da comunidade de origem (International Labour Office, 1931, p. 222-223). Sobre o trabalho nativo, ver Ferreras (2012, p. 305-324).

18 Ver League of Nations (1924, p. 737) e International Labour Office (1931, p. 223). 
condições que não existem. [...] existe a mão de obra simplesmente. Que os homens sejam negros, amarelos, de todas as cores que vocês quiserem, azuis, verdes, essas distinções não existem. Todos eles são cidadãos". ${ }^{19}$ Se a escravidão era uma realidade colonial, não podia afetar os países americanos que eram independentes. Esse posicionamento fez com que fosse eliminada a menção às regiões na pesquisa encomendada, embora foram mantidos os "indígenas" como seu objeto.

Dessa forma, o problema estava nas colônias formais. O trabalho era visto como um meio para civilizar os nativos, ao mesmo tempo que as potências colonizadoras pretendiam acabar com a escravidão. Porém, era preciso sustentar a administração colonial para que o projeto civilizador continuasse. Isso levava a colocar em valor os diversos recursos existentes nas colônias em um contexto de escassa oferta de mão de obra, agravado depois da Primeira Guerra. ${ }^{20}$ As administrações coloniais reclamavam dos trabalhadores nativos, que não queriam abandonar suas formas tradicionais de prestação de serviços, levando à implementação de formas coercitivas para forçar os nativos a ingressar no mercado de trabalho. Se a civilização implicava o trabalho, para além dos níveis de sobrevivência tradicional, então eles tinham de ser levados a trabalhar.

As formas coercitivas experimentadas foram o trabalho obrigatório, a conscrição, os trabalhos comunitários, entre outras. Também eram sancionadas outras medidas, como a limitação da posse da terra comunitária, leis de repressão à vadiagem e o pagamento de tributos em moeda, e não em espécies, como era usual.

Os administradores coloniais pretendiam que os trabalhadores africanos fossem disciplinados como os europeus, sem compreender que o processo de constituição do mercado de trabalho na Europa tinha levado séculos. Os nativos nem sempre aceitavam essas pressões extraeconômicas e protestavam, dificultando a ação dos administradores coloniais, que recorriam à violência para inibir os protestos. ${ }^{21}$

O paternalismo presente no início do processo colonial considerava os nativos como crianças que precisavam da assistência dos europeus para superar o primitivismo. Como afirmava o ensaísta francês Marcel Rémond (1903, p. 128): "Eles são nossos irmãos, mas são os nossos irmãos mais novos, que infelizmente têm instintos primitivos, que temos que corrigir. Se a persuasão e o raciocínio são impotentes para sua melhora, será necessário utilizar meios mais acessíveis à sua compreensão."

Para o funcionamento das colônias, o Estado garantia uma cota de trabalho aos empresários, que também se valiam de outras formas de coação para

\footnotetext{
${ }^{19}$ A posição de Montarroyos foi respaldada pelos delegados da Argentina, Chile, Cuba, Uruguai e Venezuela. Ver League of Nations (1926, v. 2, p. 263-264).

20 Sobre o trabalho indígena, ver Maul (2007, p. 479). Para compreender as formas de incorporação dos nativos ao mercado de trabalho, ver Beckert (2005).

${ }^{21}$ A declaração do secretário-geral da OIT em relação aos protestos encontra-se em League of Nations (1926, v. 2, p. 443).
} 
desenvolver a produção de matérias-primas. ${ }^{22} \mathrm{O}$ trabalho forçado beneficiava vários grupos, desde os empreendedores locais até os operários das metrópoles, que se vestiam, iluminavam, aqueciam ou se alimentavam com produtos extraídos das colônias.

O darwinismo social e o evolucionismo dos membros da OIT e da SdN levavam a justificar o uso de certas formas de trabalho forçado como parte do processo civilizatório de africanos e asiáticos. Nem os defensores nem os detratores do trabalho forçado discordavam da existência de duas realidades no mundo do trabalho global. Os trabalhadores coloniais deviam ser protegidos, mas, se fosse preciso, também deviam ser obrigados a trabalhar. Os oficiais franceses informavam que os africanos, sem o estimulo oficial, não trabalhavam voluntariamente. Como apresentado em um informe oficial: “[...] temos o dever de utilizar trabalho forçado apenas em limites verdadeiramente humanos e altamente remuneradores. $\mathrm{O}$ nativo não tem nenhum rigor para o trabalho, que só aceitará se for forçado"²3

Por sua vez, os latino-americanos, que ao longo da década de 1920 rejeitaram a categoria de trabalho indígena, mantiveram a diferenciação para com outras regiões do mundo, justificando-se no fato de que não existiam indígenas porque eles não estavam isolados da sociedade. ${ }^{24}$ Os latino-americanos não desafiavam a hegemonia europeia, mas tentavam manter a missão civilizatória para seus Estados. Seriam eles os que controlariam o disciplinamento em seus territórios. O mesmo pode ser aplicado aos casos do Japão e da Índia. Os delegados governamentais desses países rebatiam as críticas realizadas por seus próprios delegados trabalhistas ou de outros países, defendendo uma via civilizatória própria, que consistia em um processo autônomo de industrialização e de adequação aos parâmetros trabalhistas ocidentais. ${ }^{25}$

A OIT se propunha regulamentar o trabalho nas colônias, e para isso era preciso algum tipo de acordo entre os países coloniais, fosse de maneira formal ou informal. Essa regulação vinha embasada no Código de Trabalho Nativo, já mencionado. O racismo científico fazia do trabalho forçado uma necessidade. Os coloniais eram preguiçosos que precisavam dos europeus, fossem eles seus algozes ou protetores, para viabilizar sua inserção na economia-mundo.

Em 1929, a OIT conseguiu discutir o trabalho forçado ao aprovar a realização de uma pesquisa para a elaboração de uma futura convenção sobre o tema. Novamente, os membros latino-americanos da OIT não participaram do comitê que discutiu a convenção. A rejeição da medida teve como justificativa

\footnotetext{
${ }^{22}$ A denúncia dessa utilização dos trabalhadores nativos encontra-se em League of Nations (1926, v. 2, p. 438-442).

${ }^{23}$ Esse texto é parte do informe da França sobre as colônias, titulado "Extrait du rapport politique 769 de septembre 1920 au sujet de la main-d’œuvre" (apud Fall, 1993, p. 13).

${ }^{24} \mathrm{O}$ delegado uruguaio, César Charlone, afirmava que ao menos em seu país não havia mais indígenas. Por sua vez, o delegado argentino, Manuel Pinto, defendia a tese de que a assinatura da Constituição da OIT era entendida como o fim da diferenciação entre os diversos grupos de trabalhadores. Ver League of Nations (1926, v. 1, p. 267-268)

${ }^{25}$ Ver, por exemplo, a defesa do delegado governamental do Japão, sr. Takada, sobre as condições do trabalho em seu país e a relação com a industrialização em League of Nations. International Labour Conference. First annual meeting. Washington, 1919. Washington: International Labor Office, 1919, p. 159.
} 
o fato de negar a existência dessa forma de trabalho, dado que o trabalho nativo estava protegido ou não, sendo essa a única forma de trabalho forçado que eles aceitavam. Os países europeus, por sua vez, se colocavam como responsáveis pela situação na África e na Ásia. Na CIT de 1929, foram apresentados os resultados das pesquisas encarregadas sobre os países suspeitos de utilizar trabalho forçado: Japão, China e as regiões independentes da Índia. Também foram apresentados informes oficiosos sobre a situação em diversas colônias. ${ }^{26}$

Os debates da CIT de 1929 levaram a que a administração da OIT insistisse na necessidade de uma convenção. Eles entendiam que o trabalho forçado como forma de encaminhar o nativo ao mercado de trabalho era obsoleto, pouco rentável e contrariava as normas sociais. Sua extinção devia preceder a introdução do trabalho livre. Os representantes dos governos, pelo contrário, pretendiam que a convenção não fosse tratada, porque interferiria na administração colonial. ${ }^{27}$

Os debates de 1929 para a realização de uma consulta sobre o trabalho indígena e forçado são centrais na compreensão dos argumentos em torno dos quais girava o trabalho forçado. Podemos afirmar que esses mesmos argumentos retornam toda vez que há necessidade de requerer trabalho extraordinário nos momentos de expansão econômica, de incorporação de novas fronteiras produtivas ou de trabalho não qualificado. As cinco perguntas do informe solicitado pela OIT aos países-membros relacionadas com o incentivo ao trabalho nativo discutidas na CIT de 1929 foram as seguintes: 1) o trabalho requerido pelas lideranças locais; 2) a relação entre trabalho forçado e impostos; 3) a liberdade de associação e sindicalização; 4) a quantidade de horas que deviam ser trabalhadas; e 5) a criação de uma instância de controle do trabalho forçado.

Os representantes operários foram contrários à primeira pergunta, o trabalho requerido pelas lideranças locais, porque entendiam que dessa forma se facilitava a continuidade da venda da mão de obra nativa aos empresários coloniais intermediada pelos poderes territoriais. Os representantes britânicos defendiam-na porque essas práticas não podiam ser ignoradas, e não era possível impor o capitalismo na África e na Ásia sem considerar as tradições locais. Os britânicos incorporaram a pergunta no questionário se posicionando como defensores dos interesses dos nativos e cumprindo o rol de mandatários assinado pela $\mathrm{SdN} .^{28}$

Sobre a segunda questão, novamente os trabalhadores entendiam que obrigar os nativos a pagar os impostos coloniais era uma forma encoberta de contribuir para o processo de proletarização. O representante do governo holandês foi enfático ao alentar que em regiões desmonetizadas o pagamento dos impostos fosse com trabalho, e não em dinheiro. A pergunta foi incluída. ${ }^{29}$

\footnotetext{
${ }^{26}$ Ver League of Nations (1929, v. 1, p. 35-62 e 953-964); informes sobre China, Índia e Japão estão nas p. 256-259; os informes oficiosos estão nas p. 234-253, entre os quais Porto Rico, por seu vínculo com os Estados Unidos. 27 International Labour Office. International... 1929. Op. Cit., p. 223.

${ }^{28}$ Para o debate sobre esse primeiro ponto, International Labour Office. International... 1929. Op. Cit., pp. 518 a 524, 975 e 976. A posição britânica está nas p. 520 e 521.

29 Ibid., p. 525-527, e 977-978.
} 
A terceira pergunta, relacionada com o direito de associação, foi apresentada pelos representantes dos trabalhadores, que entendiam que era necessário estender a organização operária às colônias, possibilitando que os nativos se reconhecessem como trabalhadores e, portanto, atuando como conhecedores de seus direitos em uma economia capitalista. A pergunta foi aceita porque as organizações operárias contribuíam para a eliminação do trabalho forçado. ${ }^{30}$

O quarto ponto de discussão era uma proposta da bancada trabalhista que pretendia igualar a carga de trabalho colonial à metropolitana em oito horas diárias e 40 semanais. Os representantes governamentais britânicos e sul-africanos defenderam a possibilidade de incorporar uma pergunta para estender a jornada de trabalho por causa da baixa produtividade nas colônias. Porém, prevaleceu a posição dos operários. ${ }^{31}$

\section{Os debates de 1929 para a realização de uma consulta sobre o trabalho indigena e forçado são centrais na compreensão dos argumentos em torno dos quais girava o trabalho forçado}

O controle do trabalho forçado foi o último ponto em discussão. A proposta de um comitê permanente para controlar o trabalho forçado não era consenso. Os países coloniais arguiram que essa era uma forma de ingerência nos assuntos internos das colônias, solicitando que os informes fossem enviados pelos próprios Estados, e não por uma agência reguladora. Como forma de lograr um acordo, os trabalhadores propuseram que esse comitê fosse para aqueles países que não haviam ratificado a convenção, pelo que obtiveram o apoio dos países favoráveis ao fim do trabalho forçado. ${ }^{32}$

Depois do debate sobre o questionário de 1929 e com algumas das respostas na mão, a OIT discutiu em 1930 uma convenção sobre o trabalho forçado. Cinco dos oito grandes poderes coloniais foram favoráveis: Grã-Bretanha, Itália, Japão, Holanda e Espanha, enquanto Bélgica, França e Portugal foram contrários, tendo ainda um significativo número de delegados que preferiram se abster ou não votar. ${ }^{33}$

A posição portuguesa foi embasada em uma "questão de princípios", mas França e Bélgica procuraram pequenos entraves, como que o trabalho comunitário não fosse limitado a 60 dias ou que pudessem ser utilizadas as Forças Armadas em trabalhos públicos. A França tinha preparado sua delegação oficial cuidadosamente. O representante do governo era o senegalês Blaise Diagne, deputado por seu país no Parlamento francês e socialista como o também

\footnotetext{
30 lbid., p. 528-530, e 979-980.

${ }^{31}$ Ibid., p. 531-538, e 984-985.

32 International Labour Office. International... 1929. Op. Cit., pp. 539 a 548

33 O resultado da votação está em League of Nations (1930, v. 1, p. 333).
} 
francês Albert Thomas, o secretário-geral da OIT. Diagne votou contra a convenção. Ele, que fora o organizador das tropas coloniais durante a Primeira Guerra, entendia que a recruta militar dava continuidade ao processo de valorização das colônias (Alcock, 1971, p. 90). Mesmo assim, a Convenção no 29, "Sobre o Trabalho Forçado", foi aprovada.

V

A Convenção 29 no é um marco na definição do trabalho forçado. No artigo 2º, este foi definido como: "[...] todo trabalho ou serviço exigido de uma pessoa sob a ameaça de sanção e para o qual não se tenha oferecido espontaneamente". Da forma com que foi especificado, estavam excluídos os trabalhadores prestando serviços militares. O trabalho forçado não poderia fazer parte das obrigações dos cidadãos, fora o Exército, ou dos presidiários. A única possibilidade em que os Estados podiam requerer que seus cidadãos prestassem serviços seria em casos de emergência comunitária, como as catástrofes naturais, ou naqueles serviços cívicos que já eram obrigatórios. ${ }^{34}$

As primeiras ratificações desse convênio mostram o interesse de alguns países em controlar a escravidão e o tráfico, para além do nome da convenção. Em 1931, os signatários foram Grã-Bretanha, Irlanda, Libéria e Suécia. Nesse momento, a Libéria era questionada pelo uso de trabalho forçado e por exportar trabalhadores, pelo que a assinatura foi obrigatória (Sundiata, 1974, p. 110111). Em 1932, os países que aderiram foram Austrália, Bulgária, Dinamarca, Espanha, Japão e Noruega. ${ }^{35}$

$\mathrm{Na}$ mesma sessão da CIT, foram aprovados outros dois instrumentos legais que também são considerados parte do Código de Trabalho Nativo, as Recomendações no 35, "Sobre Compulsão Indireta ao Trabalho", e a nํ36, "Sobre a Regulação do Trabalho Forçado ou Obrigatório". O Corpo de Administração da OIT pretendia tratar também do contrato do trabalhador colonial e de sua duração, mas a oposição da França o inviabilizou. ${ }^{36}$ A perspectiva era a de consolidar um corpo legal que limitasse o trabalho forçado, e os países que já tinham tomado iniciativas nesse sentido pressionaram pela adoção de medidas restritivas, principalmente nas colônias.

Nesse período de experimentações legais e extremos políticos que foi a década de 1930, percebemos uma alta dose de pragmatismo, que obrigava a ceder em alguns pontos para avançar em outros. A necessidade de se diferenciar dos inimigos políticos e ideológicos obrigava as potências a tomar medidas que subordinavam os fatores econômicos às urgências das alianças. A França, por exemplo, mudou suas políticas coloniais em 1936 com a vitória da Frente

\footnotetext{
34 Ver Organização Internacional do Trabalho, Convenção no 29. Sobre o Trabalho Forçado ou Obrigatório. Disponivel em: <http://www.lo.org/ilolex/portug/docs/C29.htm>. Acesso em: 8 jun. 2015. Em outras línguas, o título é simplesmente: "Sobre o Trabalho Forçado".

35 Ver Organização Internacional do Trabalho, Convenção no 29. Op. cit. A Commonwealth estava na liderança das assinaturas. Vale lembrar que até o momento há oito países que não ratificaram essa convenção, entre eles China, República da Coreia e Estados Unidos.

${ }^{36}$ A aprovação de ambas as recomendações e seu debate estão em League of Nations (1930, v. 1, p. 338 e 341). Para o Contrato de Trabalho nas colônias, ver International Labour Office (1931, p. 226-227). Lembrando que convenção é um tratado internacional não vinculante, e recomendação é uma normativa complementar.
} 
Popular, passando a ser favorável a uma alteração do estatuto do trabalhador colonial, aproximando-se da OIT. No meio das mudanças e da radicalização ideológica da década de 1930, continuou o interesse pela obtenção de trabalho que garantisse a continuidade dos processos de produção de commodities. A aprovação e a ratificação da Convenção no 29 não impediam a continuidade do trabalho forçado por outras vias.

Em 1935, nesse contexto de rápidas mudanças ideológicas e de alto pragmatismo, foi discutido o recrutamento de trabalhadores, visando a aumentar a oferta de trabalho livre. Enquanto o desenvolvimento das colônias demandava mais trabalho, a OIT propunha eliminar três categorias de agentes recrutadores: a liderança local, o funcionário colonial e o recrutador profissional. Em compensação, recomendava que os trabalhadores na agricultura ou aqueles que precisassem se deslocar aos centros produtivos pudessem ser acompanhados por suas famílias, o que levaria o nativo a se oferecer livremente no mercado. Outra questão preocupante eram as migrações de longa distância, como as dos indianos em direção à África do Sul, ao Malaia e ao Ceilão; ou dos chineses à Indonésia e às ilhas do Pacífico. As migrações eram realizadas por contrato, mas os trabalhadores tinham de pagar suas passagens. Os debates permitiram a aprovação da Convenção n⿳0 50, "Relativa à Recruta de Trabalhadores Indígenas", que regulou várias dessas preocupações (Alcock, 1971, p. 94). ${ }^{37}$

A última tentativa de controlar o trabalho forçado realizado antes da Segunda Guerra Mundial foi em 1939, quando foram apresentadas duas convenções. Estas foram aprovadas quase sem debate. A essa altura, o trabalho forçado era um tema menor, e isso explica sua aprovação instantânea. Essas convenções resultam importantes para compreender como avançaram os debates até esse momento, porém não tiveram nenhum impacto imediato.

Como complemento à Convenção nํㅜ 50, foi aprovada a Convenção n⿳0 64, "Relativa aos Contratos de Trabalho dos Trabalhadores Indígenas", que estabelecia um padrão para os contratos de trabalhos e uma série de regulações no ato da contratação, como controles médicos, verificação das condições legais do contratante, entre outras. Como contraparte, foi dada uma série de garantias aos empresários na Convenção no 65, “Convenção das Sanções Penais para Trabalhadores Indígenas". Nesta eram estabelecidas penalidades, que podiam chegar à prisão, dos trabalhadores que não respeitassem os acordos, fosse porque queriam voltar ao local de origem, fosse porque queriam mudar de unidade produtiva. Duas últimas recomendações foram aprovadas, dando um marco definitivo ao Código de Trabalho Nativo durante o período colonial: a Recomendação no 58 , que estabelecia o limite temporal

\footnotetext{
${ }^{37}$ A Convenção no 50 pode ser consultada em: Organização Internacional do Trabalho. Convenção nº 50 Relativa à Recruta de Trabalhadores Indígenas. Disponível em: <http://www.lo.org/dyn/normlex/en/ $\mathrm{f}$ ? $\mathrm{p}=1000: 12100: 0:$ NO::P12100 INSTRUMENT ID,P12100_LANG CODE:312195,es:NO>. Acesso em: 14 dez. 2013. Os debates para a aprovação da convenção estão em League of Nations (1936, p. 390-405).
} 
para os contratos, e a Recomendação $\mathrm{n}^{\mathrm{0}} 59$, que criava a inspeção do trabalho indígena. ${ }^{38}$

Os representantes dos trabalhadores foram contrários às sanções por abandono do âmbito da produção. A resposta foi que elas seriam suprimidas assim que possível, sendo a situação internacional a principal desculpa. A suspeita era de que a Convenção n⿳o 65 favorecia o abuso dos contratantes, dado que não precisariam respeitar as condições de trabalho; o medo das sanções seria suficiente para a continuidade das tarefas. As melhoras relativas outorgadas pela Convenção ํㅜ 64 eram compensadas com as fortes medidas repressivas. Nenhuma convenção, nem mesmo as de trabalho forçado, estabelecem penalidades para os empresários. Essas convenções de 1939 só foram ratificadas por pouquíssimos países e depois da Segunda Guerra Mundial, quando o clima político tinha mudado.

A guerra, considerada um estado de exceção, permitiu a imposição de sanções e aprofundou a exploração sem controles, com a escusa da ameaça externa. A Segunda Guerra Mundial se configurou como um momento de refluxo nos direitos dos trabalhadores coloniais. A situação trabalhista tinha voltado ao estado anterior ao processo normativo, restabelecendo-se o trabalho forçado, tanto no caso do Eixo quanto no dos Aliados. Os países aliados aduziram que o retorno ao período anterior se devia às necessidades da guerra, alegando que em caso de vitória seria possível uma solução definitiva, tentando contornar os descontentamentos que surgiriam. De fato, em 1944, ainda durante a guerra, o comandante da França Livre, Charles De Gaulle, prometeu que o trabalho forçado seria abolido em 1949. A promessa foi realizada na Conferência Africana Francesa, na cidade de Brazzaville, no Congo francês (Fall, 1993, p. 271 e segs.). A utilização do trabalho forçado tinha perdido definitivamente 0 apoio da França. Só a Grã-Bretanha continuava formalmente com sua política tradicional contraria à utilização do trabalho forçado e escravo.

VI

Como podemos ver, "escravidão" e "trabalho forçado" não são sinônimos na nomenclatura internacional. Em princípio, as organizações internacionais marcaram diferenças entre ambas as formas de coação das pessoas. A criação da SdN junto com a OIT teve repercussões múltiplas e levou a tratamentos próprios.

Os debates sobre a escravidão tinham uma longa trajetória, como mencionamos no início, e essa trajetória esteve fortemente influenciada pelas

\footnotetext{
${ }^{38}$ Ver Organização Internacional do Trabalho. Convenção no 64 Contrato de Emprego de Trabalhadores Indígenas. Disponível em: <http://www.lo.org/dyn/normlex/en/f?p=NORMLEXPUB:1210O:O::NO:1210O:P12100_ INSTRUMENT_ID:312209:NO>; Organização Internacional do Trabalho. Convenção no 65 Sanções Penais de Trabalhadores Indigenas. Disponível em: <http://www.lo.org/dyn/normlex/en/f?p=NORMLEXPUB:12100:O:N O:12100:P12100_INSTRUMENT_ID:312210:NO>; Organização Internacional do Trabalho. Recomendação no 58 Contrato de Trabalho de Trabalhadores Indígenas. Disponível em: <http://www.lo.org/dyn/normlex/en/f?p=NO RMLEXPUB:12100:O::NO:12100:P12100_INSTRUMENT_ID:312396:NO>; e Organização Internacional do Trabalho. Recomendação no 59 Inspeções do Trabalho Indígena. Disponível em: <http://www.lo.org/dyn/normlex/en/f?p =NORMLEXPUB:12100:O::NO:12100:P12100_INSTRUMENT_ID:312397:NO>. Acesso em: 14 dez. 2013.
} 
conjunturas políticas e econômicas. Desde as decisões do governo da GrãBretanha, passando pelas abolições nas Américas, foi sendo determinado um tipo especifico de luta contra a escravidão, assim como campos discursivos e compromissos específicos em relação à propriedade da pessoa e sobre as formas de organização do trabalho.

\section{A guerra, considerada um estado de exceção, permitiu a imposição de sanções e aprofundou a exploração sem controles, com a escusa da ameaça externa}

Novos eventos e situações levaram as potências europeias a estabelecerem as formas de exploração aceitável dos trabalhadores e as relações entre as práticas que podiam ser toleradas como abusivas ou não. Por exemplo, se nos países de influência islâmica existia o harém e o concubinato, como complementos do matrimônio, estes tiveram de ser transformados em casamentos múltiplos. A repulsa ocidental perante os matrimônios múltiplos era acompanhada pela tolerância por serem matrimônios. O modus vivendi europeu se espalhava em diferentes regiões do mundo, e as instituições de outras regiões deviam se lhes assemelhar. $\mathrm{O}$ sistema de harém era vinculado ao tráfico de pessoas, e o concubinato era apresentado como uma forma de escravidão encoberta. Portanto, os prejuízos europeus com as relações poligâmicas ou de poliginia podiam ser combatidos de forma mais sutil, interrompendo o fluxo de pessoas e sua vinculação com o tráfico, mantendo as práticas culturais e sociais, mas apresentadas de forma aceitável.

Nesse sistema de divisão de incumbências, o tráfico e a escravidão foram matéria da $\mathrm{SdN}$, que estabeleceu entre seus membros algum consenso em relação a seu significado. O consenso possível foi contra a propriedade e o transporte de pessoas para sua comercialização. Fora dos países ocidentalizados, isso era muito vago, mas suficiente para constituir instituições que lidassem com a questão e legitimando organizações que colaboravam formal ou informalmente com a SdN e a OIT, como a Anti Slavery. Porém, a falta de definições deixava em aberto zonas cinzentas que, em alguns casos, deviam ser esclarecidas.

A principal zona cinzenta era justamente a questão trabalhista. O que fazer com a situação colonial? O que fazer com os nativos coloniais que não estavam dispostos a trabalhar e que preferiam manter suas formas tradicionais de organizar suas vidas e economias? Como civilizar sem o trabalho? A obrigação do trabalho ou o pagamento de impostos era uma solução que às vezes conduzia à escravidão, como acontecera no Congo do rei Leopoldo da Bélgica $\mathrm{e}$ durante a febre da borracha nas florestas do Putumayo, na virada do século XX, e de novo na Libéria da década de 1930.

A solução parecia ser a regulação, que também tinha seus problemas. Nem todos os países viam a universalização da regulação como factível em seus 
territórios. Os países americanos se opuseram fortemente à possibilidade de que regulações coloniais fossem aplicadas em seus territórios. O mesmo pode ser dito dos países asiáticos independentes, como o Japão. O trabalho forçado encobria realidades que não podiam ser pormenorizadas por uma lei universal.

Neste artigo, tratamos da especialização discursiva e legal de um campo, como é a escravidão, de suas possibilidades analíticas e de sua globalização, tentando mostrar como os diversos atores se posicionaram segundo seus interesses e suas tradições jurídicas e culturais.

\section{Referências bibliográficas}

ALCOCK, Antony. History of the International Labour Organisation. Londres: The McMillan Press, 1971.

ALLAIN, Jean. The legal definition of slavery into the twenty-first century. In: (Ed.). The legal understanding: from the historical to the contemporary. Oxford: Oxford University Press, 2012. . The slavery conventions: the Travaux Préparatoires of the 1926 League of Nations Convention and the 1956 United Nations Convention. Leiden: Martinus Nijhoff, 2008.

BECKERT, Sven. From Tuskegee to Togo: the problem of freedom in the empire of cotton. The Journal of American History, v. 92, n. 2, set. 2005.

DRESCHER, Seymour. From consensus to consensus: slavery in international law. In: ALLAIN, Jean (Ed.). The legal understanding of slavery: from the historical to the contemporary. Oxford: Oxford University Press, 2012.

FALL, Babacar. Le travail forcé en Afrique-Occidentale française (1900-1946). Paris: Karthala, 1993. FERRERAS, Norberto O. La modernité intégrée par les peuples indigènes. L'Organisation internationale du travail et l'Amérique latine, la question des peuples indigènes et tribaux. In: AARÃO REIS, Daniel; ROLLAND, Denis (Org.). Modernités nationales, modernités importées: entre ancien et nouveau monde, XIXe-XXIe siècle. Paris: L'Harmattan, 2012.

FRANCE, MINISTERE DES AFFAIRES ETRANGERES. Convention sur le régime des spiritueux en Afrique et protocole signés à Saint-Germain-en-Laye, le 10 septembre 1919. In: Recueil de législation \& jurisprudence coloniales. Paris: Marchal \& Billard, out./dez. 1922. n. 4, p. 763-766. GRENOUILLEAU, Olivier. Qu'est ce que l'esclavage? Une histoire globale. Paris: Gallimard, 2014. INTERNATIONAL LABOUR OFFICE. The International Labour Organization: the first decade. Boston: World Peace Foundation, 1931.

LEAGUE OF NATIONS. ASSEMBLY, SIXTH COMMITTEE. Question of slavery. Report presented to the Sixth Assembly by the Sixth Committee. Rapporteur: Viscount Cecil of Chelwood, delegate of the British Empire. Genebra, 1925.

. International Labour Conference. Eighth annual meeting. First annual meeting. Washington,

1919. Washington: International Labor Office, 1919. . International Labour Conference. Eighth annual meeting. Geneva, 1926. Genebra: International Labor Office, 1926. v. 1. . International Labour Conference. Eighth annual meeting. Geneva, 1926. Genebra: International Labor Office, 1926. v. 2, p. 443.

. International Labour Conference. Fourteenth annual meeting. Geneva, 1930. Genebra: International Labor Office, 1930. v. 1. . International Labour Conference. Sixth annual meeting. Geneva, 1924. Genebra: International Labor Office, 1924. . International Labour Conference. Twelfth annual meeting. Geneva, 1929. Genebra: International Labor Office, 1929. v. 1. . International Labour Conference. Twentieth annual meeting. Geneva, 1936. Genebra: International Labor Office, 1936. . The records of the First Assembly. Meetings of the committees. Genebra, 1920a. v. I. . The records of the First Assembly. Meetings of the comittes. Genebra, 1920b. v. II. . The records of the Second Assembly. Meetings of the committees. Genebra, 1921. v. II. 
LEAGUE TO ENFORCE PEACE. The Paris Covenant for a League of Nations: text of the plan adopted by the Paris Peace Conference, April 28, 1919. Nova York, 1919. p. 13.

LOVEJOY, Paul E.; HOGENDORN, Jan S. Slow death for slavery: the course of abolition in Northern Nigeria, 1897-1936. Cambridge: Cambridge University Press, 1993.

MAUL, Daniel. Human rights, development and decolonization: the International Labour Organization, 1940-1970. Hampshire: Palgrave Macmillan, 2012.

. The International Labour Organization and the struggle against forced labour from 1919 to the present. Labor History, v. 48, n. 4 p. 477-500, 2007.

MIERS, Suzanne. Slavery and abolition in XXth century. In: RODRÍGUEZ, Junius. Slavery in the modern world: a history of political, social, and economic oppression. Santa Barbara: ABCCLIO, 2011.

. Slavery in the twentieth century: the evolution of a global pattern. Walnut Creek: Alta Mira Press, 2003.

REMOND, Marcel. La main-d'oeuvre dans les colonies françaises. Paris: Librairie Cerf, 1903.

STAHN, Carsten. The law and practice of international territorial administration: Versailles to Iraq and beyond. Cambridge: Cambridge University Press, 2008.

SUNDIATA Ibrahim K. Prelude to scandal: Liberia and Fernando Po, 1880-1930. The Journal of African History, v. 15, n. 1, 1974.

UNITED STATES OF AMERICA. DEPARTMENT OF THE STATE. Report of the Commission of Inquiry into the existence of slavery and forced labor in the Republic of Liberia. Monrovia, Liberia, September 8, 1930. Washington, Government printing office, 1931. 